\title{
Electric Vehicle Impact Assessment Study Based on Data-logged Vehicle and Driver Behavior
}

\author{
Nirav Shah ${ }^{\# 1}$, Baekhyun Cho ${ }^{\# 1}$, Frederik Geth $^{\# 2}$, Kristien Clement ${ }^{\# 2}$, Peter Tant ${ }^{\# 2}$, Johan Driesen ${ }^{\# 2}$ \\ AVL Powertrain $\mathrm{UK}^{\# 1}$, K.U.Leuven Belgium ${ }^{\# 2}$ \\ nirav.shah@avl.com, frederik.geth@esat.kuleuven.be
}

\begin{abstract}
Traditionally, the impact of charging electric vehicles in the electricity grid is determined through scenario-analysis and based on statistical data. In this paper, instead of making assumptions on driving behavior, the energy consumption was calculated with measured driving profiles of conventional vehicles in order to quantify the future impact on the grid in more detail. As a function of the penetration of the Plug-in Hybrid Electric Vehicles and Battery Electric Vehicles, the increase in the peak power requirement in the grid is assessed.
\end{abstract}

\section{INTRODUCTION}

Alternative technology vehicles are generating lots of interest these days. Especially, Plug-in Hybrid Electric Vehicles (PHEV) and Battery Electric Vehicles (BEV) are gaining popularity among automotive OEMs. Several models are being manufactured currently and even more are planned for the mass roll-out in the coming years.

A PHEVs can drive a certain distance in electric-only mode, and when the battery is depleted, a fuel powered engine is started to provide power for a larger range. BEVs operate only in the electric mode. Both PHEVs and BEVs are charged by plugging into electric outlets or by means of wireless (inductive) charging stations in the low-voltage distribution grid. Since these vehicles consume a significant amount of electrical energy, their power demand may lead to an increase in the magnitude and frequency of undesireable consumption peaks. As a results, it is expected that EVs have an impact on the electricity system, especially when penetration levels increase.

To quantify this impact, four questions on vehicle and driver behavior will be are discussed in this paper. How much energy is needed to charge to vehicle? Is there a charging station or outlet available when parked? How much time is there to charge? Where is the vehicle located in the grid?

\section{VEHICLE ENERGY CONSUMPTION}

\section{A. Previous versus new approach}

In previous work [1], the availability of a charging connection for a fleet of vehicles was determined using stochastic data from mobility studies [2]. In this study, information is available on the frequency and time of vehicles arriving at and leaving from work. From $07 \mathrm{~h} 00$ to $10 \mathrm{~h} 00$ the probability that people leave for work is highest, from $16 \mathrm{~h} 00$ to $19 \mathrm{~h} 00$ the probability of arriving back home is highest. During the day or evening, trips with different goals are found, e.g. family visits, shopping, eduction. On average, 2.23 trips per day are made per vehicle. An example of

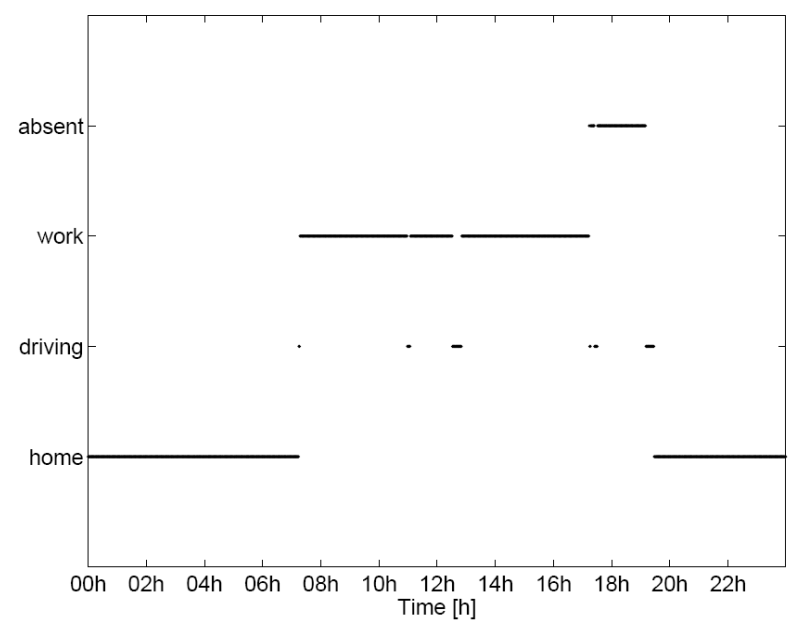

Fig. 1. Sample of the availability analysis.

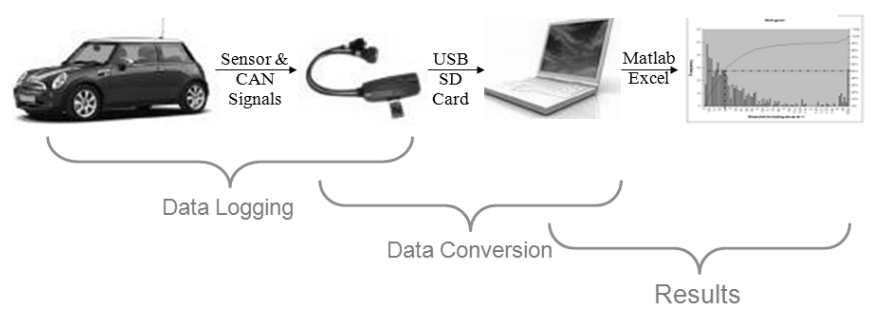

Fig. 2. Overview of steps from data-logging to analysis

profile determined by the Availability Analysis (AA) is shown in Fig. 1. In this model, it is assumed that the energy consumption rate while driving is constant.

In contrast, a new approach uses data from Real World (RW) vehicles and driving cycles. This allows for variable energy consumption rates to be taken into account. Instead of stochastically generated profiles, actual measured data is used. Fig. 2 gives an overview of the data flow and the subsequent phases of composing the RW profiles: datalogging, data conversion and statistical analysis.

B. Data-logging

As EVs are not widely available yet, conventional vehicles were used to obtain the vehicle driving speed profiles and other related data. First, the vehicle is instrumented and then the software is configured to give the specific time series signals and other sensor data. All data is collected and saved on an SD card, including CAN bus data and signals from the sensors. While the vehicle is in motion, data can also be captured live, by attaching the USB connector of the 
datalogger to the computer. However, since the experiment concerned general customers driving to work / school / shopping centre, etc., data was collected using the SD card. As soon as the cards are received from the customers, the data is converted to an appropriate format and validated. Finally, the data is used in the model to get the energy consumption of each vehicle. The calculation method steps are explained in the following paragraphs.

Several petrol-fueled vehicles were equipped with a datalogger and were driven for approximately one week each. Around 700 trips were collected with time-series data of analogue and digital signals. The vehicle specification and a list of the signals logged during the trips for further analysis are shown in Table I and II below.

TABLE I

VEHICLE SPECIFICATION

\begin{tabular}{|l|r|r|}
\hline \multicolumn{1}{|c|}{ Parameter } & \multicolumn{1}{c|}{ Value } & \multicolumn{1}{c|}{ Unit } \\
\hline Vehicle Mass & 1065 & $\mathrm{~kg}$ \\
\hline Drag Coefficient & 0.33 & - \\
\hline Tire Rolling Coefficient & 0.01 & - \\
\hline Vehicle Frontal Area & 1.97 & $\mathrm{~m}^{2}$ \\
\hline Transmission Efficiency & 95 & $\%$ \\
\hline
\end{tabular}

TABLE II

PARTIAL List OF SignAls LogGed

\begin{tabular}{|l|l|}
\hline \multicolumn{1}{|c|}{ Analog } & \multicolumn{1}{c|}{ Digital } \\
\hline Vehicle Speed & Air Condition Switch \\
\hline Engine Speed & Brake Pedal Switch \\
\hline Gear Signal & Engine State \\
\hline Ambient Temperature & \\
\hline Engine Temperature & \\
\hline
\end{tabular}

\section{Statistical Analysis}

The focus of this analysis was on three output parameters:

1. Total electrical energy required for daily driving.

2. Opportunities for charging the electric vehicles.

3. Impact of charging on the electricity grid.

These parameters are calculated using the vehicle speed data from the CAN data bus, the vehicle dynamics model, the absolute trip start time, accessory load on the vehicle and efficiency of the powertrain components.

\section{Assumptions}

The performance of the Electric Motor (EM) is assumed to be equal to the performance of the conventional petrol engine used to drive the vehicle specified in Table 1. In essence, this means that the electric motor is selected in such a way that it meets the driving profile of conventional vehicles. The main use of the EM model is to calculate the power loss or efficiency of drivetrain.

Several base-load assumptions were made based on the usage of entertainment system, navigation, exterior lights and air conditioning (AC). In case of exterior lighting a constant electrical load is applied. Using the information of trip start time from the logged data when the trips had started between $20 \mathrm{~h} 00$ to $08 \mathrm{~h} 00$ the next day. A constant load for the AC was added if the AC ON signal was registered. These constants were taken from [3] and are shown in Table III.
TABLE III

ACCESSORY LOADING CONSTANTS [3]

\begin{tabular}{|l|r|}
\hline \multicolumn{1}{|c|}{ Accessory } & Power (W) \\
\hline Entertainment System & 52 \\
\hline Navigation System & 100 \\
\hline Electric Power Steering & 100 \\
\hline Cooling Fan & 300 \\
\hline Brake Lights & 157 \\
\hline Air Conditioning Compressor & 2300 \\
\hline HVAC fans & 283 \\
\hline
\end{tabular}

\section{E. Modelling}

For the sake of simplicity, the EM speed is considered to be same as the engine speed. Thus, an equivalent number of gears in the transmission is assumed and due to this the EM runs in its most efficient region. Also, when the vehicle speed is zero, the EM speed is considered to be zero. As the batteries in the EVs or PHEVs have sufficient capacity and are powerful enough to provide for the accessory load, there is no need to run the EM while the vehicle is stationary. Also, there is no delay to set the vehicle in motion in an EM driven vehicle as compared to conventional vehicle. It is required to stop the engine and crank the engine, using the starter motor, from zero speed to idle speed, to move the vehicle. This creates a delay for a request to stop and start.

The EM produces highest torque when run at lower speed, typically below 1000-3000 rpm, depending on the technology. Therefore, the acceleration performance required to propel the vehicle for the given driving profiles, can be achieved with a smaller sized electric motor and / or with multiple gearing.

The vehicle dynamics and fundamental physics equations used for the analysis are:

$$
\begin{aligned}
& F(t)=m \cdot(a(t)+g \cdot R c)+\frac{\rho \cdot C d \cdot A f \cdot V^{2}(t)}{2} \\
& P(t)=F(t) \cdot V(t) \\
& E(t)=\int_{0}^{t} P(t) d t
\end{aligned}
$$

First, the force balance is formulated (1), this includes acceleration, rolling resistance and wind resistance forces. The traction power required can be calculated using the instantaneous power equation (2), which is the multiplication of the instantaneous force and speed. Since the EM speed is assumed to be same as engine speed, except at zero vehicle speed, when the EM speed is also zero, the required instantaneous torque can be calculated. From the power loss map of the EM, which needs torque and speed as inputs, the instantaneous power loss is calculated. Next, these losses are added to the traction power required by the vehicle and subtracted from the traction power while the EM is working as a generator. Using (3), the total energy required by the EM from the battery and the amount of energy recovered and stored in battery is determined.

Second, the energy required by the accessories and subsystems is calculated. Accessory loads are divided into three categories based on their use. 
1. Constant Accessory Loads: This includes entertainment and navigation systems, electric power steering equipment and cooling fans. From the data logs, the trip start time and trip end time are known, and therefore also the duration of the trip. Using this information and (3), the average energy use for each trip was calculated.

2. Temperature Dependent Accessory Loads: This includes the $\mathrm{AC}$ compressor itself and the $\mathrm{AC}$ fan load. AC use can be calculated using the AC data log. Using the constant loads value as stated in Table III of $\mathrm{AC}$ fan load and AC compressor, AC energy use can be calculated.

3. Motion Dependent Accessory Loads: This includes lighting loads. Lighting loads are further divided into brake and signal lights and exterior lighting. Using the brake pedal switch data, logged during driving, and the constant brake light load value from Table III, the energy use for brake lights is obtained. If the trip start time is between $20 \mathrm{~h} 00$ to $08 \mathrm{~h} 00$ then the exterior lights are assumed to be switched on.

Summing up all the above accessory loads will give us the total accessory consumed energy. Using (4), the total energy usage per trip is calculated.

$$
E_{\text {used }}=\left(E_{\text {BattOut }}+E_{\text {BattIn }}+E_{\text {Accessories }}\right)
$$

In the charge-depleting mode, the driving efficiency $(\mathrm{kWh} / \mathrm{km})$ is calculated from the total energy use obtained from the model described above and the trip distance, which is derived from the recorded daily speed profile of each vehicle.

If the battery capacity of the vehicle is assumed to be, for example $10 \mathrm{kWh}$ and $\mathrm{x}_{1}, \mathrm{x}_{2} \ldots \mathrm{x}_{\mathrm{n}}$ represents the respective energy used by $n$ vehicles, ultimately $10-x_{1}, 10-x_{2} \ldots 10-x_{n}$ $\mathrm{kWh}$ will be required to fully charge the battery.

The start and end time of each individual trip, the time when the vehicle is available for charging, and the time required to fully charge the vehicle are also collected or determined.

\section{GRID IMPACT}

\section{A. Scenario and assumptions}

The PHEVs modeled in this research have a nominal storage capacity of $11 \mathrm{kWh}$. Because of life expectancy optimization, the usable capacity is restricted to $80 \%$, equivalent to $8.8 \mathrm{kWh}$ (battery-to-wheel). Because of the power electronics efficiency in the charger and battery charge acceptance efficiency, taken at $88 \%$ in total [4], $10 \mathrm{kWh}$ is required from the point of connection to the grid (grid-towheel). The vehicle-to-grid enabled charger, a concept discussed in [5], is bidirectional and has a maximum output power of $+/-4 \mathrm{~kW}$. In other words, the vehicles are capable of injecting electrical energy back into the grid to offer for example grid-supporting services. At $4 \mathrm{~kW}$, the charging time is 2.5 hours, which for example is substantially shorter than a night's worth of sleep. A typical $20 \mathrm{~A}, 230 \mathrm{~V}$ outlet allows for a maximum output power $4.6 \mathrm{~kW}$. To allow for voltage deviations within $+/-10 \%$, not to be exceeded for more than $5 \%$ of the time according to the EN50160 standard [6], without tripping a $20 \mathrm{~A}$ circuit breaker, an effective maximum charger power of $4 \mathrm{~kW}$ is determined.

Fast charging is not considered because of the residential context of this research. To allow for faster charging, wiring in the households would have to be reinforced and perhaps the household's contracted power would have to increase. Both incur costs and are assumed unlikely choices because of the relatively short charging times of the PHEVs modeled in this study. Furthermore, fast charging for PHEVs is not that critical. If the battery runs out, the trip can still be continued using the conventional engine. The maximum penetration of PHEVs in Belgium is predicted by [7] at $30 \%$ by 2030 .

The grid impact-analysis is performed using a scenario for a distribution grid and its coupled loads, i.e. a number of Flemish households and PHEVs.

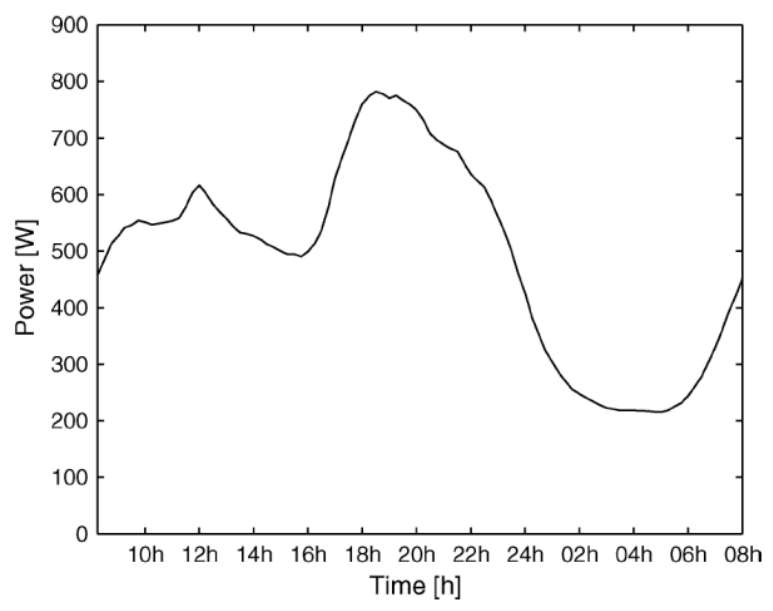

Fig. 3: Household load during winter

A synthetic load profile (SLP) for Flemish households is obtained from the Flemish regulator for the electricity and gas markets [8]. Two profiles, one for summer and one for winter, with a duration of 24 hours and a resolution of 15 minutes, are selected from this set. In Fig. 3, the winter SLP is shown for an average household electricity consumption of $3500 \mathrm{kWh}$ [8]. Typical household connections in Flanders are single-phase $230 \mathrm{~V} / 40 \mathrm{~A}$ and three-phase $400 \mathrm{~V} / 32 \mathrm{~A}$, leaving ample room to slow-charge an $\mathrm{EV}$ at home.

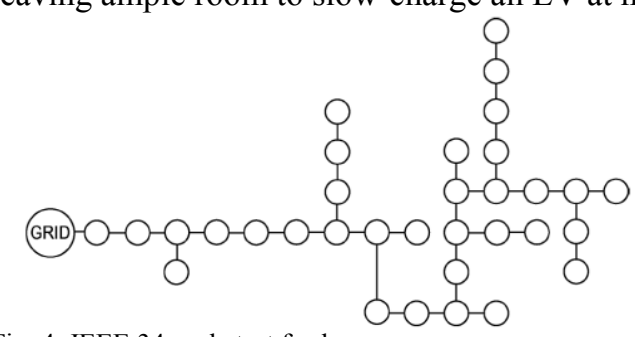

Fig. 4: IEEE 34-node test feeder

The simulation is based on the IEEE 34-node test feeder [9], shown in Fig. 4. It is a radial network, normally simulated at a medium voltage level of $24.9 \mathrm{kV}$, but for this 
research the grid was rescaled to $230 \mathrm{~V}$ and its impedances were adapted to represent a residential low voltage distribution grid.

\section{B. Methodology}

In each 24-hour cycle, a household SLP is randomly selected from the available set, belonging to a scenario (winter or summer), and assigned to each node. PHEV penetration levels of $10 \%, 20 \%$ and $30 \%$ are compared with a reference case without PHEVs. The placing is random.

Without coordination, the scheduling is straightforward: each individual vehicle starts charging when a connection is available and for as long as the battery is not fully charged. The charging ends at disconnection from the grid or when the battery is fully charged.

With coordination, the scheduling of the charging of the vehicles is optimized for a given objective, e.g. grid losses or voltage deviation minimization. In this research, this optimization problem is formulated as a quadratic programming problem. Such an approach requires extensive knowledge of the system to perform the optimization, so primarily it shows the potential of coordination. On-line coordination systems however may use these results to benchmark their performance.

In quadratic programming, the objective function is a quadratic function of several variables, in this case the power of the PHEV chargers at each time step, subject to linear constraints. The PHEV owners are assumed to indicate the point in time to batteries need to be fully charged, but cannot intervene in the charging process. As soon as the vehicle is at home, the vehicle is connected to the grid and the coordination algorithm then determines the charging schedule. The charger power can be curtailed (variable power) and can also be bidirectional.

The chosen objective is to minimize the grid power losses, which are treated as a reformulation of the nonlinear power flow equations. This nonlinear minimization problem is then tackled through sequential quadratic optimization. A highlevel description of the formulation of the problem is given here. An in-depth explanation of the coordination algorithm and the optimal power flow solving through sequential quadratic programming, is provided in [1] and [10].

$$
\begin{gathered}
\min \sum_{t=1}^{t_{\text {max }}} \sum_{l=1}^{\text {lines }} R_{l} \cdot I_{l, t}^{2} \\
\text { s.t. }\left\{\begin{array}{l}
\forall t, \forall n \in\{\text { nodes }\}: P_{\text {PHEV }, \text { min }} \leq P_{\text {PHEV }, n, t} \leq P_{P H E V, \text { max }} \\
\forall n \in\{\text { nodes }\}: \sum_{t=1}^{t_{\text {max }}} P_{P H E V, n, t} \cdot \Delta t \cdot x_{n}=C_{\text {max }} \\
\forall t, \forall n \in\{\text { nodes }\}: 0 \leq C_{n, t} \leq C_{\text {max }} \\
\forall t, \forall n \in\{\text { nodes }\}: U_{\text {lowerlimit }, n, t} \leq U_{n, t} \leq U_{\text {upperlimit }, n, t} \\
x_{n} \in\{0,1\}
\end{array}\right.
\end{gathered}
$$

The grid losses minimization is formulated as objective function (5) subject to constraints (6). The constraints describe the vehicle model. Following the order of the equations: the charging and discharging power limits on connection power, the requirement of a fully charged battery at the requested time, the limits on the battery state of charge and the grid voltage deviation limits. Binary variable $X_{n}$ is zero if there is no PHEV present and is one if there is a PHEV present at node $\mathrm{n}$.

\section{Assumptions and interpretation}

The concrete benefits of coordinated charging depend on a number of factors. Distribution grid strength varies significantly, depending primarily on the age of the infrastructure and the increased loading since its inception. Effectively, each grid will need to be studied, to be able to determine the maximum level of PHEV penetration.

The household profiles are typical for Belgium. The time of arriving at home after work coincides with the peak in household electricity demand. Consequently, without coordination, the impact may be higher in Belgium than in countries where a different electricity consumption pattern is found.

Typical Belgian contracted household power and electric outlet power allow for slow charging, but in some countries the grid capacity is much more limited.

To roll out an eventual on-line coordination mechanism, certain information streams (e.g. electricity market prices), measurements (e.g. local power quality), communication infrastructure (e.g. power line communication, GPRS) are required. Smart meters may function as a gateway for such functionality.

Summarizing, the results determined in this research are applicable for the prepared scenario, with a coordination strategy based on perfect knowledge of the next day.

\section{RESULTS}

A load flow analysis is performed to assess grid efficiency losses and voltage variation. The backward-forward sweep method is used to calculate node currents, line currents and node voltages [11]. All the loads are assumed to operate at constant power. The maximum voltage deviation and grid losses are calculated as the average of 1000 samples.

\section{A. Uncoordinated charging}

The RW profiles are more random compared to the AA ones. It is still the case that most vehicles start to charge during the evening; however the charging profile is flatter but fluctuates. The maximum aggregated charging power for a fleet PHEVs is now much lower, with only $8 \mathrm{~kW}$ required for a penetration rate or $30 \%$.

Fig. 5 shows the cumulative charging profile for the AA driving profiles; Fig. 6 shows the cumulative charging profile for the RW driving profiles. It is obvious that the AA driving profiles are based on probability density functions. If more vehicles are connected to the grid, the cumulative charging profile does not change, however the peak increases to almost $24 \mathrm{~kW}$. 

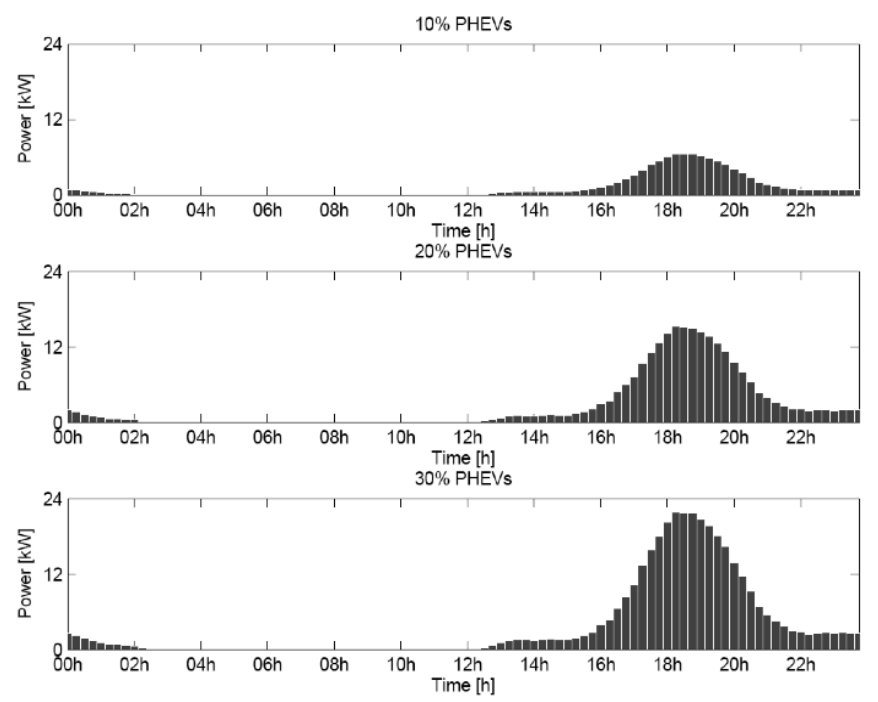

Fig. 5. Charging profile for uncoordinated charging and AA driving profiles
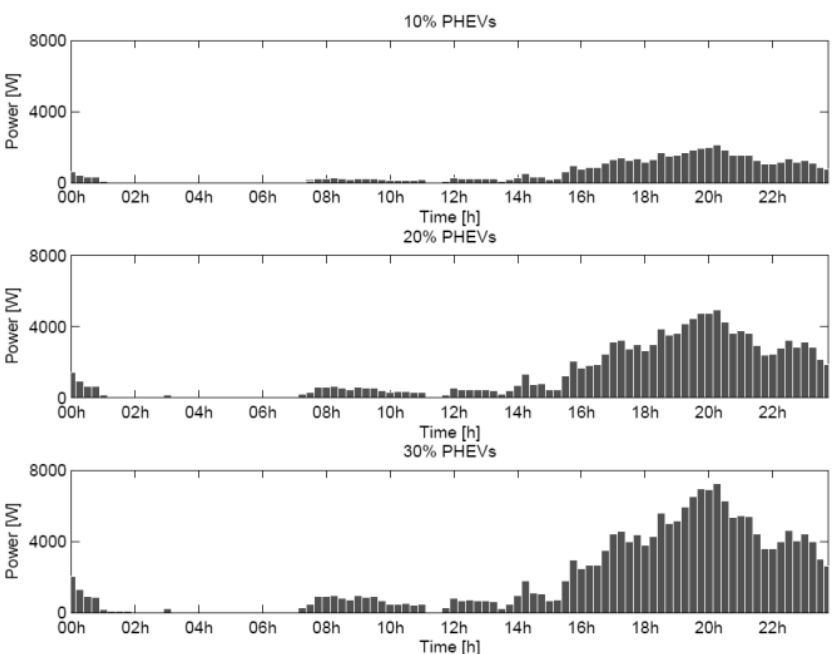

Fig. 6. Charge profile for uncoordinated charging and RW profiles

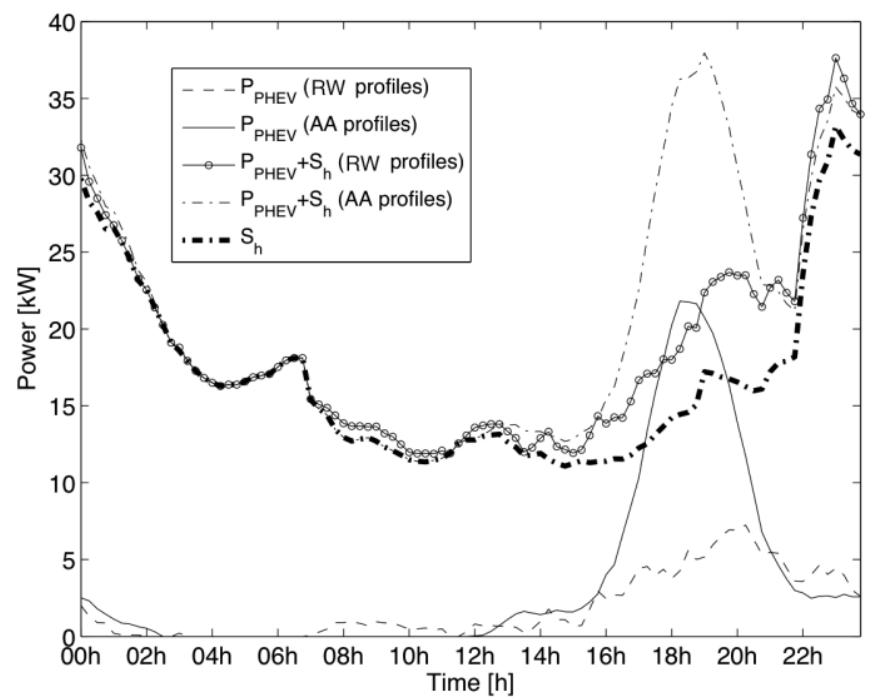

Fig. 7. Cumulative charge profile for uncoordinated charging and household loads
Fig. 7 compares the AA and RW profiles when added to the household loads. It is noted that not only the peak power is higher, but also the energy consumption is higher when the AA profiles are used instead of the RW ones. The required energy depends on the consumption of the vehicles during the day. If the vehicles drive less distance than what is available in the all-electric range, there still is energy left in the batteries when they start charging and consequently their grid electricity consumption is lower. Table IV shows the grid power losses and voltage deviations for both profile sets.

TABLE IV

RATIO OF POWER LOSSES TO TOTAL POWER AND VOLTAGE DEVIATIONS [\%] FOR UNCOORDINATED CHARGING

\begin{tabular}{|c|l|r|r|r|r|}
\cline { 2 - 6 } \multicolumn{1}{c|}{} & Grid parameter & $\mathbf{0} \%$ & $\mathbf{1 0} \%$ & $\mathbf{2 0} \%$ & $\mathbf{3 0} \%$ \\
\hline \multirow{2}{*}{ RW } & Power losses & 1.9 & 1.9 & 2.0 & 2.1 \\
\cline { 2 - 6 } & Voltage deviations & 6.2 & 6.5 & 6.7 & 6.9 \\
\hline \multirow{2}{*}{ AA } & Power losses & 1.9 & 2.0 & 2.2 & 2.4 \\
\cline { 2 - 6 } & Voltage deviations & 6.2 & 6.4 & 6.6 & 7.0 \\
\hline
\end{tabular}

\section{B. Coordinated charging and discharging}

Again, the two driving profile sets are compared and the grid impact is investigated, but now coordination is applied through the vehicle-to-grid enabled chargers. Table $\mathrm{V}$ shows the results for the RW and AA profiles. The losses remain virtually the same for both sets.

TABLE V

RATIO OF POWER LOSSES TO TOTAL POWER AND VOLTAGE DEVIATIONS [\%] FOR COORDINATED CHARGING

\begin{tabular}{|c|l|r|r|r|r|}
\cline { 2 - 6 } \multicolumn{1}{c|}{} & Grid parameter & $\mathbf{0} \%$ & $\mathbf{1 0} \%$ & $\mathbf{2 0} \%$ & $\mathbf{3 0} \%$ \\
\hline \multirow{2}{*}{ RW } & Power losses & 1.9 & 1.8 & 1.9 & 2.0 \\
\cline { 2 - 6 } & Voltage deviations & 6.2 & 5.1 & 5.1 & 5.3 \\
\hline \multirow{2}{*}{ AA } & Power losses & 1.9 & 1.9 & 2.0 & 2.2 \\
\cline { 2 - 6 } & Voltage deviations & 6.2 & 5.1 & 5.4 & 6.1 \\
\hline
\end{tabular}

Fig. 8 and Fig. 9 show the cumulative charging profile for the vehicles with coordination and respectively the RW and AA profiles. The time of charging is shifted to the night. In the evening, energy is injected into the grid to minimize the power losses. The cumulative power peak is only slightly larger for the AA profiles compared with the RW ones. There is neither electricity consumption nor injection during the day because the vehicles are absent at that time. Because of the lack of charging during the day, the batteries are more depleted when the vehicles arrive at home in the evening.

With the $\mathrm{V} 2 \mathrm{G}$ enabled charging patterns added to the household profiles, the benefit of coordination becomes apparent. Fig. 10 shows how the combined power demand is very flat. The consumption peaks during the evening have disappeared in both sets due to the vehicles discharging when the household load is high. 

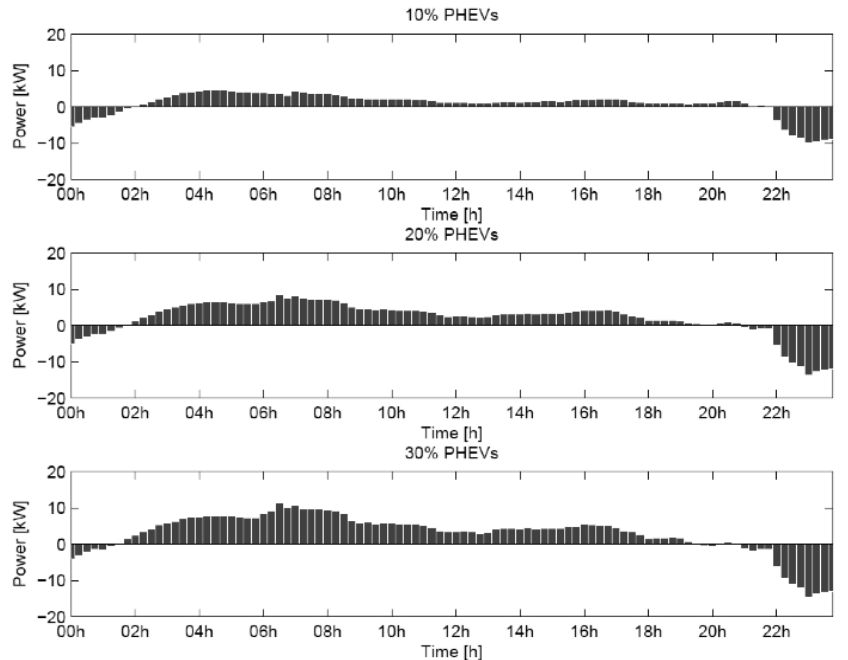

Fig. 8. Cumulative charging profile for coordinated charging and RW profiles
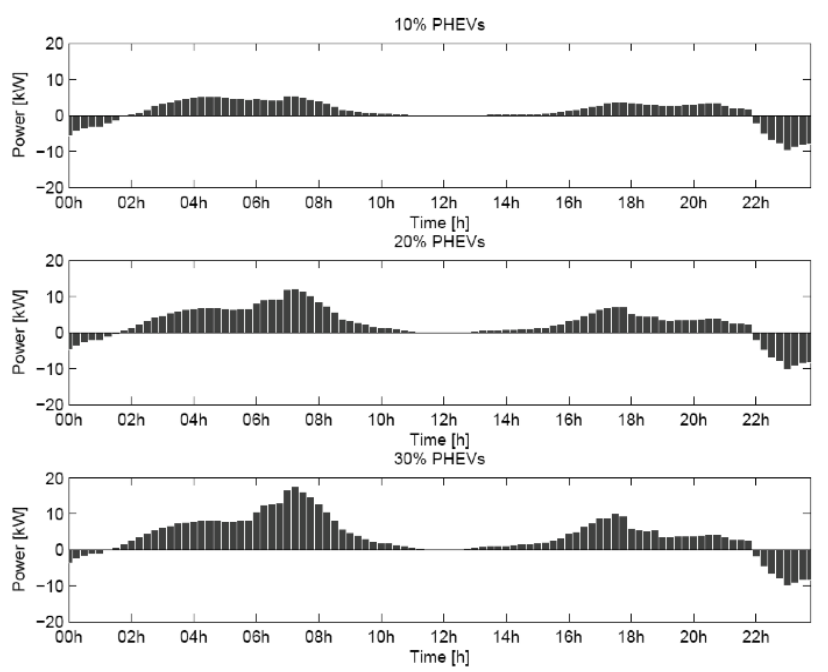

Fig. 9. Cumulative charging profile for coordinated charging and AA driving profiles

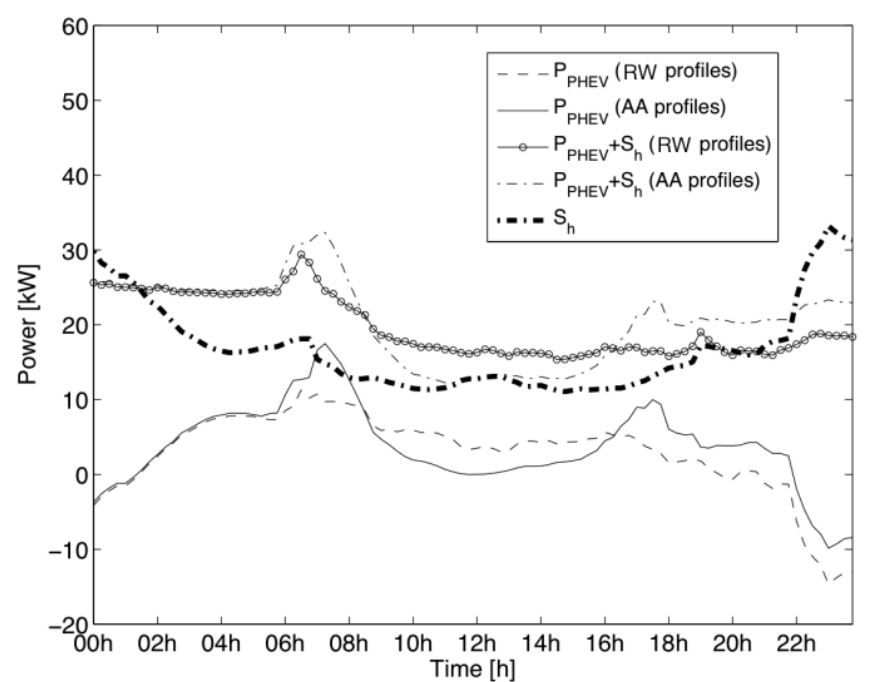

Fig. 10. Cumulative charging profile for coordinated charging and household loads
The difference between the maximum charging power of the two profile sets has largely disappeared with coordination. The vehicles now also charge during the day, although the discharging during peak hours is more limited compared to the case with the AA profiles. The energy required to charge the vehicles is now more or less the same for both sets.

\section{CONCLUSIONS}

The quality of input data for simulations is important for the interpretation of the results. Two data sets were considered for the PHEV grid impact analysis performed in this study. The AA driving profiles are based on stochastic data from a mobility study and the Real World profiles are based on real world driving cycles.

The Real World profiles were determined through an electrical vehicle energy consumption model with driving behavior measured in normal petrol-fuelled personal vehicles.

In the low voltage distribution grid analysis, the AA driving profiles showed significantly higher peak charging load than RW profiles. Higher charging peaks put added strain on the grid, particularly in the case without charging coordination. Higher losses and voltage deviations are seen in the case with the AA driving profiles.

When coordinated charging is applied, the difference in peak power decreases. The optimization behind the coordination is able to flatten the aggregated power profile because the vehicles have ample time available for charging.

\section{REFERENCES}

[1] Clement K., Haesen E., Driesen J. "The Impact of Charging Plug-In Hybrid Electric Vehicles on a Residential Distribution Grid," IEEE Transactions on Power Systems, VOL. 25, NO. 1, February, 2010; pp. 371-380.

[2] Institute for road safety research (SWOV), Research commuting behaviour (ovg), 2007. [Online]. http://www.swov.nl.

[3] Rosario, L.C.; Economou, J.T.; Luk, P.C.K.; , "Multi-agent load power segregation for electric vehicles," Vehicle Power and Propulsion, 2005 IEEE Conference, vol., no., pp. 6 pp., 7-9 Sept. 2005

[4] M. Duvall, E. Knipping, M. Alexander, L. Tonachel, and C. Clark, "Environmental Assessment of Plug-In Hybrid Electric Vehicles. Volume 1: Nationwide Greenhouse Gas Emissions," Electric Power Research Institute, Palo Alto, CA, vol. 1015325, 2007.

[5] W. Kempton and J. Tomic, "Vehicle-to-grid power fundamentals: Calculating capacity and net revenue," Journal of Power Sources, vol. 144, Jun. 2005, pp. 268-279.

[6] EN50160, Voltage Characteristics of Electricity Supplied by Public Distribution Systems, 1999.

[7] S. Logghe, B. Van Herbruggen, and B. Van Zeebroeck, "Emissions of road traffic in Belgium, tmleuven," Tremove, Jan. 2006. [Online]. Available: http://www.tmleuven.be/

[8] Flemish Regulator of the Electricity and Gas Market / Vlaamse Reguleringsinstantie voor de Elektriciteits- en Gasmarkt (VREG), Load profiles of residential and non-residential electricity consumers for the year 2007. [Online]. Available: http://www.vreg.be.

[9] W. H. Kersting, "Radial distribution test feeders," in Proc. IEEE Power Eng. Soc. Winter Meeting, Jan. 28-Feb. 1, 2001. [Online]. Available: http://ewh.iee.org/soc/pes/dsacom/.

[10] E. Haesen, J. Driesen, and R. Belmans, "Robust planning methodology for integration of stochastic generators in distribution grids," IET J. Renew. Power Gen., vol. 1, no. 1, pp. 25-32, Mar. 2007.

[11] W. Kersting, Distribution System Modeling and Analysis. Boca Raton, FL: CRC, 2002. 